\title{
Acaricidal activity of essential oil nanoemulsion against the African red mite (Eutetranychus africanus)
}

\author{
Thanaporn Doungnapa ${ }^{1 *}$, Jarongsak Pumnuan ${ }^{1}$, and Ammorn Insung ${ }^{1}$ \\ ${ }^{1}$ King Mongkut's Institute of Technology Ladkrabang, Faculty of Agricultural Technology, Department of Plant Production Technology, \\ Bangkok 10520, Thailand. "Corresponding author (k.thanapornmilk@gmail.com).
}

Received: 1 October 2020; Accepted: 12 January 2021; doi:10.4067/S0718-58392021000200228

\begin{abstract}
The African red mite (Eutetranychus africanus [Tucker]) is an important pest species of some economic plants. The objective of the present study was to evaluate the effectiveness of nanoemulsions consisting of citronella grass, lemongrass, clove, and cinnamon essential oils and their main chemical compounds against the African red mite; their toxicity, egg-laying inhibition, and repellent effect on the mite were determined. Essential oil nanoemulsions (nEOs) were prepared by mixing the essential oils with different surfactants and co-surfactants. Approximately 10 to 15 female mites were transferred to treated leaves placed on soaked cotton and kept in a Petri dish. Mite mortality and number of eggs laid were checked after $24 \mathrm{~h}$. As for the repellency test, the selected test consisted of dipping a half leaf into the nEOs, while the other half leaf was dipped in a control (water). The repellency rate was evaluated after $24 \mathrm{~h}$. Results revealed that citronella grass nEOs exhibited a highly toxic effect on the mite and only a $0.6 \%$ concentration caused $100 \%$ mite mortality. Geraniol, one of the main chemical compounds of citronella grass, represented the highest egg-laying inhibition at a $0.2 \%$ concentration with a mean of 0.1 egg compared with $4.7 \mathrm{eggs}$ in the control. Furthermore, nEOs from citronella grass at a $0.1 \%$ concentration were extremely repellent against the mite with $95 \%$ repellency after $24 \mathrm{~h}$. Therefore, the citronella grass essential oil nanoemulsion is appropriate for use to effectively control the African red mite.
\end{abstract}

Key words: Egg inhibition, essential oil nanoemulsion, Eutetranychus africanus, repellent, toxicity.

\section{INTRODUCTION}

The African red mite (Eutetranychus africanus [Tucker]) (Actinedida: Tetranychidae) is one of the most significant pest species for some plants (Attia et al., 2013). A wide range of damage caused by this mite pest in various plants, fruits, and a variety of ornamentals has been reported (Liburd and Rhodes, 2019). It is a very important pest in Thailand. The larvae, nymphs, and adults of the African red mite suck the fluid on the adaxial or upper side of the plant leaves and can produce many white spots on the leaves. A severe outbreak can eventually cause leaf and fruit loss (Beyzavi et al., 2013; Khanjani et al., 2017).

A chemical control is often applied to insect or mite pests because of its ease of application and high effectiveness. However, it is harmful to users, consumers, and the environment; it also results in increased mite resistance to acaricides and greater environmental risks. The search to replace the use of synthetic chemicals by other control methods is now increasing, particularly natural products which show low toxicity to non-target organisms and are approved by the consumer. In addition, they are classified as environmentally friendly due to their biodegradable characteristics (Lertsutthiwong and Rojsitthisak, 2011; Tirello et al., 2012; Chung et al., 2013). 
There are few studies regarding the use of available nanotechnology for insect or mite pest control. Plant extracts or essential oils are one of the main components of safe control strategies. Nanotechnology helps to improve the efficiency of essential oils that are oil-in-water dispersions with a variety of very small droplet sizes; moreover, they are stable over time. However, stability depends on the individual system or ingredient mixture, and low viscosity and droplet size make them a more suitable system for applications (Gao et al., 2011; Solans and Solé, 2012; Rice et al., 2013; Kwon et al., 2015; Jintapattanakit, 2018). Therefore, essential oil nanoemulsions (nEOs) from plants are very promising for use as botanical acaricides. Sarapothong et al. (2017) showed that black pepper (Piper nigrum L.) nEOs at a 1\% concentration exhibited high effectiveness against the African red mite; mite mortality was $96 \%$ and median lethal concentration $\left(\mathrm{LC}_{50}\right)$ was $0.34 \%$. These black pepper nEOs showed a moderate repellency effect; the repellency index (RI) was $42.39 \%$ to $51.67 \%$ after 24 h. Lakyat et al. (2017) reported repellent activity of lemongrass (Cymbopogon citratus [DC.] Stapf) nEOs with at very low concentration of $0.02 \%$, and the most repellent activity was against adult brown planthoppers (Nilaparvata lugens Stal; Hemiptera: Delphacidae) with 43.83\% RI.

The present study focused on evaluating high-potential nEOs for use in mite pest management. Therefore, the objective was to evaluate the effectiveness of some nEOs in terms of acaricidal, egg-laying inhibition, and repellent effects against the African red mite using the leaf dipping method.

\section{MATERIALS AND METHODS}

\section{African red mite rearing}

The African red mite (Eutetranychus africanus [Tucker]) adults were randomly collected from an organic durian (Durio zibethinus Murray) orchard in Chanthaburi province, Thailand. They were initially reared on mulberry (Morus alba L.) leaves placed on a cotton swab soaked with water on a tray to serve as their food source. Thousands of African red mite adults were reared on mulberry leaves and maintained at room temperature $\left(25 \pm 2{ }^{\circ} \mathrm{C}\right)$ and $85 \pm 2 \%$ relative humidity (RH). Each leaf was removed every 4 to $5 \mathrm{~d}$ and a fresh leaf was provided. Mite rearing and all the bioassay experiments were conducted at the laboratory of Natural Products for Pest Control Research Center (NPCRC), Department of Plant Production Technology, Faculty of Agricultural Technology, King Mongkut's Institute of Technology Ladkrabang (KMITL), Bangkok, Thailand.

\section{Plant essential oils and main chemical compounds}

The essential oils (EOs) were obtained from 13 species of medicinal plants and preliminary use allowed evaluating their effectiveness against the African red mite. The EOs were obtained from the Thai-China Flavors and Fragrances Industry Co. Ltd. in Thailand and prepared according to principles of hazard analysis and critical control point (HACCP). The EOs were from citronella grass (Cymbopogon nardus [L.] Rendle), lemongrass (C. citratus [DC.] Stapf), cinnamon (Cinnamomum bejolghota [Buch.-Ham.] Sweet), clove (Syzygium aromaticum [L.] Merr. \& L.M. Perry), black pepper (Piper nigrum L.), eucalyptus (Eucalyptus globulus Labill.), star anise (Illicium verum Hook. f.), ginger (Zingiber officinale Roscoe), sweet fennel (Foeniculum vulgare Mill. subsp. vulgare var. dulce [Mill.] Batt.), kaffir lime (Citrus hystrix DC), cassumunar ginger (Z. cassumunar Roxb.), Siam cardamom (Amomum cardamomum L.), and sweet basil (Ocimum basilicum L.)

Chemical compounds found in effective EOs from different medicinal plants were verified by column chromatography. The silica gel G-60 was used for chromatography as the stationary phase, while the petroleum and ethyl alcohol solvent mixture was selected as the mobile phase. The aliquot of each fraction was analyzed by thin layer chromatography (TLC) (Saenmanot et al., 2018). The pure fraction examples of EOs were analyzed for their major components by gas chromatography-mass spectrometry (GC-MS) according to Pumnuan and Insung (2016b). The main chemical compounds appearing in effective EOs, geraniol, citral, and eugenol, were ordered from Sigma-Aldrich (St. Louis, Missouri, USA).

\section{Preparation of essential oil emulsions and main chemical compound nanoemulsions}

The 13 EOs were diluted in water with Tween-20 as an emulsifier or surfactant. The EO emulsions contained different surfactant concentrations when properly dissolved that were used for further bioassay experiments. 
Selected effective EOs and their main chemical compounds such as geraniol, citral, and eugenol were diluted in water with surfactants. The EO particles appearing in the emulsions were resized into nanoparticles by adding the cosurfactant at different concentrations. In the present experiment, Tween-20 (hydrophilic-lipophilic balance (HLB) = 16.7) and Tween-60 (HLB = 14.9) were used as primary surfactants, whereas polyethylene glycol 400 (PEG400) $(\mathrm{HLB}=$ 13) was used as co-surfactant as follows. Firstly, each EO or the main chemical compound was merged with the primary surfactant, Tween-20 or Tween-60 at 1:1, 1:1.5, 1:2, 1:2.5, 1:3, 1:3.5, 1:4, and 1:4.5 (1:1 is $100 \mu \mathrm{L}: 100 \mu \mathrm{L})$ for $10 \mathrm{~mL}$. Co-surfactant polyethylene glycol (PEG400) (Smix) was added to each solution at 1:1, 1:1.5, 1:2, 1:2.5, 1:3, 1:3.5, 1:4, and 1:4.5. The prepared EOs were then placed into a nanoparticle size analyzer (NanoPlus Zeta, Otsuka Electronic Co., Ltd., Osaka, Japan) to measure particle size. When EO particles in the emulsion were larger than $100 \mathrm{~nm}$, the emulsion was passed through a high pressure homogenizer to minimize particle size, which was then measured again. These prepared essential oil nanoemulsions (nEOs) and their main chemical compound nanoemulsions (nMC) were used for further toxicity assessments.

\section{Toxicity tests}

The effectiveness of 13 EOs against the African red mite was primarily assessed by the leaf dipping method. The mulberry leaf was cut into $2.7 \mathrm{~cm}$ diameter circles and dipped for $1 \mathrm{~min}$ with each of these EOs at $2 \%$ and removed for air-drying at room temperature $\left(25 \pm 2{ }^{\circ} \mathrm{C}, 85 \pm 2 \% \mathrm{RH}\right)$ for $15 \mathrm{~min}$. Approximately 10 to 15 adult female mites were selected under a microscope and introduced to the treated leaf. Mite mortality was observed after $24 \mathrm{~h}$. Mites were determined to be dead when they did not move even if prodded with a small hairbrush. The EOs were highly effective in killing mites with more than $70 \%$ mortality; these EOs were tested in new experiments as nEOs with different concentrations. In addition, the main chemical compounds contained in the effective EOs were also verified by column chromatography as nanoemulsions.

The toxicity properties of nEOs and nMCs against the African red mite were also evaluated by the leaf dipping method. The mulberry leaf was cut into 2.7 diameter circles and dipped for $1 \mathrm{~min}$ in each nanoemulsion at different concentrations: $0.0 \%$ (water as control) and surfactants at $0.0 \%, 0.2 \%, 0.4 \%, 0.6 \%, 0.8 \%$, and $1.0 \%$. All treatments were air-dried for 15 min. Approximately 10 to 15 adult female mites were transferred to the treated leaves on soaked cotton and kept in a Petri dish. Mite mortality was observed after $24 \mathrm{~h}$. In the case that mites died in the control, Abbott's formula (Abbott, 1987) was applied according to the actual death rate as

$$
\text { Mortality }(\%)=[\mathrm{T}-\mathrm{C} / 100-\mathrm{C}] \times 100
$$

where $\mathrm{T}$ is test mortality (\%) with $\mathrm{nEOs}$ and $\mathrm{C}$ is control mortality (\%).

\section{Egg-laying inhibition test}

Egg-laying inhibition caused by $\mathrm{nEOs}$ was determined by the abovementioned method. The mulberry leaves were dipped in different concentrations of nEOs at 0.0 (water) and surfactant and co-surfactant or blank at $0.0,0.02,0.04,0.06,0.08$, 0.10 , and 0.20 for $1 \mathrm{~min}$. Treated leaves were air-dried at room temperature for $15 \mathrm{~min}$. Later, 10 to 15 adult females were released to treated leaves. The number of eggs laid by each female mite was observed under a microscope after $24 \mathrm{~h}$.

\section{Repellency and attraction test}

The response of the African red mite to seven nEOs was evaluated for repellency and attraction activity using a similar method, and the selected test was performed. The leaves cut in circles were equally divided, and the first half was dipped in nEOs at $0.02 \%, 0.06 \%$, and $0.1 \%$. Meanwhile, the other half was dipped in water or surfactant (control). Both halves were removed for air-drying at room temperature for $15 \mathrm{~min}$. Approximately 10 to 15 adult females of the African red mite were transferred, and the percentages of repellency and attraction response were determined after $24 \mathrm{~h}$.

\section{Statistical analysis}

In the present study, Abbott's formula was applied to obtain the actual mite death rate. The experiment was performed using a completely randomized design with five replicates per treatment. The data obtained were analyzed by ANOVA, and the differences among treatments were tested by Duncan's multiple range test with SAS software (SAS Institute, Cary, North Carolina, USA). As for the percentage response in terms of the repellency and attraction test, frequencies of mites in the selected test were analyzed by the $\chi^{2}$ test with SPSS software (IBM, Armonk, New York, USA). 


\section{RESULTS AND DISCUSSION}

The toxicity of EOs obtained from 13 selected medicinal plants, citronella grass, lemongrass, cinnamon, clove, black pepper, eucalyptus, star anise, ginger, sweet fennel, kaffir lime, cassumunar ginger, siam cardamom, and sweet basil in emulsions against adult African red mites revealed that EO emulsions of citronella grass, lemongrass, cinnamon, and clove at $2 \%$ were highly effective in killing the African red mite with more than $70 \%$ mite mortality (Figure 1). This concurred with the report by Insung et al. (2016), who found that EOs of citronella grass, clove, cinnamon, and lemongrass were extremely toxic against the European house dust mite (Dermatophagoides pteronyssinus). The clove EO also exhibited high insecticidal activity against adult thrips (Frankliniella schultzei) and mealybugs (Pseudococcus jackbeardsleyi) (Pumnuan and Insung, 2016b).

The four selected EOs, citronella grass, lemon grass, cinnamon, and clove, which were highly effective in killing the mite were analyzed by GC-MS to determine their chemical compounds. The citronella grass EO contained $37.97 \%$ citronella and $18.60 \%$ geraniol. Meanwhile, the lemongrass EO had the highest amount of geranyl acetal at $29.03 \%$ and $20.21 \%$ citral. In addition, the clove and cinnamon EOs had the same main active ingredient eugenol at $81.55 \%$ and 98.45\%, respectively. Sruthi et al. (2014) and Uddin et al. (2017) reported that the clove and cinnamon EOs contained approximately $80 \%$ to $90 \%$ eugenol analyzed by GC and GC-MS. Silva et al. (2011) and Hamzah et al. (2013) indicated that citronella grass EO contained the most important substances, including citronellal, citronellol, geraniol, geranial, and limonene. There were more than 80 components (Silva et al., 2011) appearing in the EOs in which the lemon grass EO had the most important substances, mainly citral, limonene, citronellal, $\beta$-myrcene, geranial ( $\alpha$-citral), and neral ( $\beta$-citral).

Nanoemulsions of the four most effective EOs against the African mite were made from emulsions using surfactants and co-surfactants at appropriate ratios. Surfactants provided better emulsion stability than co-surfactants. The use of less surfactant than co-surfactant resulted in unstable emulsions. The selected surfactants must be able to decrease interfacial tension to a very small amount to encourage the dispersion process during nanoemulsion preparation to obtain the desired type of nanoemulsion (i.e., oil/water, water/oil, or bicontinuous) (McClements, 2011; Solans and Solé, 2012; Kwon et al., 2015; Komaiko and McClements, 2015; Jintapattanakit, 2018). Particle size analysis by the dynamic light scattering technique indicated that the particle size of citronella grass, clove, and cinnamon EOs ranged from 11.80 to $18.70 \mathrm{~nm}$ diameter, polydispersity index from 0.04 to $0.15 \mathrm{M}_{\mathrm{n}}\left(\mathrm{M}_{\mathrm{n}}\right.$ is the number average molecular weight), and zeta potential from -6.23 to $-7.92 \mathrm{mV}$. Meanwhile, the largest particle size of lemongrass EO was $188.77 \mathrm{~nm}$. Finally, this particle was reduced with a high pressure homogenizer at $30000 \mathrm{psi}$ to a $34.57 \mathrm{~nm}$ diameter, polydispersity index of $0.19 \mathrm{M}_{\mathrm{n}}$, and zeta potential of $-4.39 \mathrm{mV}$. The particle size of the main chemical compounds geraniol, citral, and eugenol ranged from 11.07 to $18.00 \mathrm{~nm}$ diameter and polydispersity index from 0.02 to $0.19 \mathrm{M}_{\mathrm{n}}$, and zeta potential from -10.30 to $3.38 \mathrm{mV}$. The polydispersity index is an indicator of their quality with respect to size distribution (Danaei et al., 2018). The zeta potential values greater than 30 $\mathrm{mV}$ indicate physical stability (Marsalek, 2014). Unfortunately, poor zeta potential values were detected in this study.

Figure 1. Percentage mortality of the African red mite caused by different plant essential oils at $2 \%$ concentration after $24 \mathrm{~h}$ by the leaf dipping method.

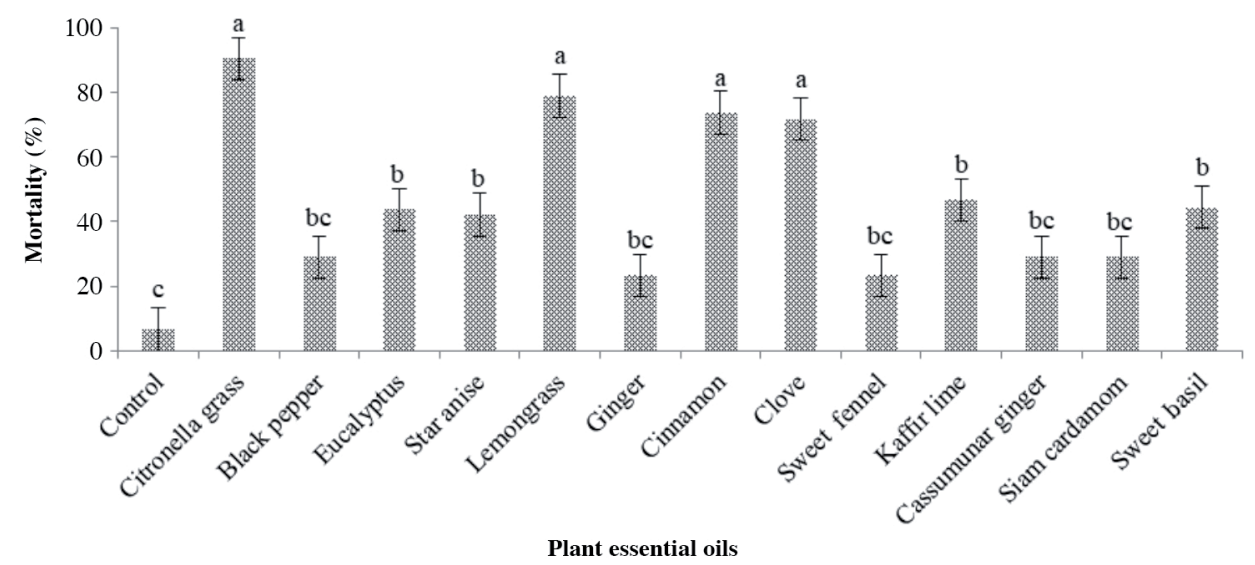

The same letter above each column indicates nonsignificant differences according to Duncan's multiple range test. 
The acaricidal activity assessment reported that citronella grass nEOs at $1 \%$ and $2 \%$ could completely control the African red mite (4.0\% to $28.8 \%$ and $71.7 \%$ to $90.4 \%$ mortality, respectively), followed by cinnamon, clove, and lemongrass nEOs. It would appear that the nEOs at $1 \%$ exhibited more than three times the activity of EOs, particularly citronella grass $\mathrm{EO}$ at $1 \%$ that caused $28.6 \%$ mite mortality, whereas $\mathrm{nEO}$ produced $100 \%$ mite mortality. A similar result was observed for the other plant EOs. It should be noted that mite percentage mortality among nEOs at $1 \%$ and $2 \%$ was not significantly different (Table 1). It was previously mentioned that the emulsion with smaller particles of plant EOs could work better than larger particles. Additionally, using co-surfactant was a very important technique to prepare nEOs and their mixture could promote effectiveness on the mite.

The highest concentration of all the nEOs caused the highest mortality rate of the African red mite. Citronella grass $\mathrm{nEO}$ at $0.4 \%$ killed up to $97.2 \%$ of the mites, followed by geraniol nMCs at $96.7 \%$ mortality; however, there was nonsignificant difference among them. All surfactants prepared by mixing main surfactants and co-surfactants at different ratios (A to D, Table 2) and $0.4 \%$ concentration exhibited mite mortality from $60.1 \%$ to $89.7 \%$, while other nEOs and nMCs showed $66.5 \%$ to $90.0 \%$ and $55.1 \%$ to $88.3 \%$ mortality, respectively. However, there were significant differences among a group of treatments. The result was satisfactory when citronella grass $\mathrm{nEO}$ at $0.6 \%$ to $1.0 \%$ could completely kill the mites, and there were nonsignificant differences among the concentrations (Table 2). When comparing the effectiveness of citronella grass $\mathrm{nEO}$ and geraniol $\mathrm{nMC}$ with others at $0.4 \%$, this implied that other treatments had a lower percentage mortality of the African red mite. All the surfactants also had a high toxic effect on the mite, particularly at $0.4 \%$ to $1.0 \%$, which caused $60.1 \%$ to $100 \%$ mite mortality. Results indicated that many compounds existing in EOs could usually work better together than a chemical compound alone; there was also some synergistic effect depending on the mixture between the precursor and surfactant. Results were disappointing when the performance of $\mathrm{nEO}$ and $\mathrm{nMC}$ formulas showed generally lower mite mortality than citronella grass $\mathrm{nEO}$ alone. At $0.6 \%$, they produced from $87.2 \%$ to $98.3 \%$ mortality compared with $100 \%$ by citronella grass $\mathrm{nEO}$. This could be due to the influence of the surfactant and co-surfactant. Mixtures of plant EOs usually exhibited more toxicity to the tested mites. There are very few reports regarding the effectiveness of citronella grass EO to control the mite pest. Pumnuan and Insung (2016a) demonstrated that lemongrass and citronella grass EOs applied at $3 \mu \mathrm{g} \mathrm{L}^{-1}$ air caused 100\% and 82.5\% mortality, respectively, on mushroom mite (Dolichocybe indica) using the fumigation method. In addition, Saad et al. (2017) proved that citronella EO had extensive insecticidal properties such as contact toxicity, repellency, and ovipositional deterrence on Bemisia tabaci, causing high mortality when applied at $6.66 \mu \mathrm{L} \mathrm{L}^{-1}$ air.

Experimental results of egg-laying inhibition caused by nEOs, nMCs, and surfactants at $0.02 \%$ to $0.2 \%$ by the leaf dipping method revealed that the highest concentration greatly reduced the number of eggs laid. The clove nEO showed that the minimum number of eggs laid was 2.7 eggs per adult female at the $0.02 \%$ concentration, followed by eugenol, citral, cinnamon, and citronella grass EOs with 3.1,3.2,3.4, and 3.4 eggs, respectively; there was nonsignificant difference among them. Geraniol at $0.2 \%$ also produced a high egg-laying inhibition effect with 0.1 eggs, followed by citronella grass EO with 0.3 eggs, and there was nonsignificant difference between them. The highest surfactant concentration had more effect on the number of eggs laid. In the control (water), the number of eggs laid was 4.7 eggs, approximately six times more than for surfactant at $0.2 \%$ (Table 3 ). When it was compared to nEOs, a larger number of eggs laid was obtained. Additionally, nEOs at a low concentration could inhibit the number of eggs similar to the surfactant. The nMCs results generally tended to show more activity at higher concentrations, especially geraniol that had the best performance.

Table 1. Percentage mortality of the African red mite caused by plant essential oil emulsions and essential oil nanoemulsions at $1 \%$ and $2 \%$ concentrations by the leaf dipping method.

\begin{tabular}{|c|c|c|c|c|}
\hline & \multicolumn{2}{|c|}{ Essential oil emulsion } & \multicolumn{2}{|c|}{ Essential oil nanoemulsion } \\
\hline & $1 \%$ & $2 \%$ & $1 \%$ & $2 \%$ \\
\hline & 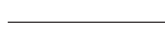 & - & 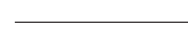 & - \\
\hline Citronella grass & $28.6 \pm 6.2 \mathrm{Ac}$ & $90.4 \pm 2.6 \mathrm{Ab}$ & $100.0 \pm 0.0 \mathrm{Aa}$ & $100.0 \pm 0.0 \mathrm{Aa}$ \\
\hline Lemongrass & $28.8 \pm 6.8 \mathrm{Ac}$ & $78.9 \pm 8.4 \mathrm{ABb}$ & $86.8 \pm 28.4 \mathrm{Aa}$ & $100.0 \pm 0.0 \mathrm{Aa}$ \\
\hline Cinnamon & $10.7 \pm 6.2 \mathrm{Bc}$ & $73.7 \pm 11.6 \mathrm{Ab}$ & $96.2 \pm 6.3 \mathrm{Aa}$ & $100.0 \pm 0.0 \mathrm{Aa}$ \\
\hline Clove & $4.0 \pm 0.7 \mathrm{Bc}$ & $71.7 \pm 1.7 \mathrm{Ab}$ & $87.6 \pm 21.9 \mathrm{Aa}$ & $100.0 \pm 0.0 \mathrm{Aa}$ \\
\hline $\mathrm{CV}, \%$ & 30.77 & 9.32 & 19.63 & - \\
\hline
\end{tabular}

CV: Coefficient of variation.

Means in a column followed by the same uppercase letter and means in a row followed by the same lowercase letter are not significantly different $(\mathrm{P}<0.05)$ according to Duncan's multiple range test. 
Table 2. Percentage mortality of the African red mite caused by different essential oil and main chemical compound emulsions at different nanoemulsion concentrations by the leaf dipping method.

\begin{tabular}{|c|c|c|c|c|c|c|}
\hline \multirow[b]{2}{*}{ Emulsion formation } & \multicolumn{6}{|c|}{ Nanoemulsion concentration $(\%)$} \\
\hline & 0.0 (water) & 0.2 & 0.4 & 0.6 & 0.8 & 1.0 \\
\hline & & & & $\%$ & & \\
\hline \multicolumn{7}{|l|}{ Surfactant } \\
\hline $\mathrm{A}=$ Tween-20(4.0):PEG400(3.5) & $0.0 \mathrm{a}$ & 73.3ab & $89.7 \mathrm{ab}$ & $98.1 \mathrm{a}$ & $98.1 \mathrm{ab}$ & $99.0 \mathrm{ab}$ \\
\hline $\mathrm{B}=$ Tween-20(4.0):PEG400(1.0) & $0.0 \mathrm{a}$ & $84.8 \mathrm{a}$ & $88.3 \mathrm{abc}$ & $97.9 \mathrm{a}$ & $98.1 \mathrm{ab}$ & $100.0 \mathrm{a}$ \\
\hline $\mathrm{C}=$ Tween-60(4.5):PEG400(2.5) & $0.0 \mathrm{a}$ & $48.2 \mathrm{bcde}$ & $63.2 \mathrm{bcde}$ & 80.9abcd & $85.2 \mathrm{~cd}$ & 93.0abc \\
\hline $\mathrm{D}=$ Tween-60(4.5):PEG400(1.0) & $0.0 \mathrm{a}$ & $42.6 \mathrm{cde}$ & $60.1 \mathrm{cde}$ & 67.1de & $69.9 \mathrm{e}$ & $76.6 \mathrm{~d}$ \\
\hline \multicolumn{7}{|l|}{ Essential oil nanoemulsion } \\
\hline Citronella grass in A & $0.0 \mathrm{a}$ & $87.2 \mathrm{a}$ & $97.2 \mathrm{a}$ & $100.0 \mathrm{a}$ & $100.0 \mathrm{a}$ & $100.0 \mathrm{a}$ \\
\hline Lemongrass in $\mathrm{C}$ & $0.0 \mathrm{a}$ & $39.9 \mathrm{de}$ & $53.2 \mathrm{de}$ & $71.6 \mathrm{cde}$ & $84.2 \mathrm{~cd}$ & $86.4 \mathrm{~cd}$ \\
\hline Cinnamon in D & $0.0 \mathrm{a}$ & $19.3 \mathrm{ef}$ & $56.1 \mathrm{de}$ & $73.5 \mathrm{bcde}$ & 87.5abcd & $96.1 \mathrm{abc}$ \\
\hline Clove in D & $0.0 \mathrm{a}$ & 21.3def & $48.0 \mathrm{e}$ & $59.2 \mathrm{e}$ & $86.2 \mathrm{bcd}$ & $87.3 \mathrm{bcd}$ \\
\hline \multicolumn{7}{|c|}{ Main chemical compound nanoemulsion } \\
\hline Geraniol in B & $0.0 \mathrm{a}$ & $81.1 \mathrm{a}$ & $96.7 \mathrm{a}$ & $97.0 \mathrm{a}$ & $100.0 \mathrm{a}$ & $100.0 \mathrm{a}$ \\
\hline Citral in $\mathrm{C}$ & $0.0 \mathrm{a}$ & $69.8 \mathrm{abc}$ & $81.8 \mathrm{abcd}$ & $90.0 \mathrm{abc}$ & 95.0abcd & $100.0 \mathrm{a}$ \\
\hline Eugenol in D & $0.0 \mathrm{a}$ & $45.0 \mathrm{bcde}$ & $63.9 \mathrm{bcde}$ & 81.7abcd & $84.0 \mathrm{~d}$ & $90.9 \mathrm{abc}$ \\
\hline \multicolumn{7}{|l|}{ Essential oil nanoemulsion formula } \\
\hline Citronella grass:Lemongrass (3:1) & $0.0 \mathrm{a}$ & $44.2 \mathrm{bcde}$ & $66.5 \mathrm{bcde}$ & 87.2abc & 93.3abcd & $98.3 a b c$ \\
\hline Citronella grass:Cinnamon (3:1) & $0.0 \mathrm{a}$ & $43.8 \mathrm{cde}$ & $90.0 \mathrm{ab}$ & $98.3 \mathrm{a}$ & $100.0 \mathrm{a}$ & $100.0 \mathrm{a}$ \\
\hline Citronella grass:Clove $(3: 1)$ & $0.0 \mathrm{a}$ & $51.3 \mathrm{bcd}$ & $85.0 \mathrm{abc}$ & $94.6 \mathrm{a}$ & $98.3 \mathrm{ab}$ & $100.0 \mathrm{a}$ \\
\hline Citronella grass:Lemongrass $(2: 2)$ & $0.0 \mathrm{a}$ & $39.1 \mathrm{de}$ & $81.0 \mathrm{abcd}$ & $88.7 \mathrm{abc}$ & $90.0 \mathrm{abcd}$ & $95.0 \mathrm{abc}$ \\
\hline Citronella grass:Cinnamon (2:2) & $0.0 \mathrm{a}$ & $44.2 \mathrm{bcde}$ & $85.9 \mathrm{abc}$ & $95.0 \mathrm{a}$ & $100.0 \mathrm{a}$ & $100.0 \mathrm{a}$ \\
\hline Citronella grass:Clove $(2: 2)$ & $0.0 \mathrm{a}$ & $38.1 \mathrm{de}$ & 76.4abcd & $91.7 \mathrm{abc}$ & 93.3abcd & $94.7 \mathrm{abc}$ \\
\hline \multicolumn{7}{|c|}{ Main chemical compound nanoemulsion formula } \\
\hline Geraniol:Citral $(3: 1)$ & $0.0 \mathrm{a}$ & $9.2 \mathrm{f}$ & $65.2 \mathrm{bcde}$ & $93.8 \mathrm{ab}$ & $94.3 \mathrm{abcd}$ & $100.0 \mathrm{a}$ \\
\hline Geraniol:Eugenol (3:1) & $0.0 \mathrm{a}$ & $19.5 \mathrm{ef}$ & $55.1 \mathrm{de}$ & $88.3 \mathrm{abc}$ & 93.3abcd & $100.0 \mathrm{a}$ \\
\hline Geraniol:Citral (2:2) & $0.0 \mathrm{a}$ & $69.7 \mathrm{abc}$ & $88.3 \mathrm{abc}$ & $91.8 \mathrm{abc}$ & $96.7 \mathrm{abc}$ & $98.3 \mathrm{abc}$ \\
\hline Geraniol:Eugenol (2:2) & $0.0 \mathrm{a}$ & $33.9 \mathrm{def}$ & 74.2abcde & 86.3abcd & $96.7 \mathrm{abc}$ & $98.3 \mathrm{abc}$ \\
\hline $\mathrm{CV}, \%$ & & 45.79 & 27.84 & 17.40 & 9.82 & 9.32 \\
\hline
\end{tabular}

CV: Coefficient of variation.

Means in a column followed by the same letter are not significantly different $(\mathrm{P}<0.05)$ according to Duncan's multiple range test.

Table 3. Number of eggs laid by the African red mite after treated with essential oil and main chemical compound nanoemulsions at different concentrations by the leaf dipping method.

\begin{tabular}{|c|c|c|c|c|c|c|c|c|}
\hline \multirow[b]{3}{*}{$\begin{array}{c}\text { Concentration } \\
(\%)\end{array}$} & \multicolumn{8}{|c|}{ Number of eggs per female } \\
\hline & \multirow[b]{2}{*}{$\begin{array}{c}\text { Surfactant } \\
\text { A }\end{array}$} & \multicolumn{4}{|c|}{ Essential oil nanoemulsion } & \multicolumn{3}{|c|}{ Main chemical compound nanoemulsion } \\
\hline & & $\begin{array}{l}\text { Citronella } \\
\text { grass }\end{array}$ & Lemongrass & Cinnamon & Clove & Geraniol & Citral & Eugenol \\
\hline 0.0 (water) & 4.7Aa & 4.7Aa & 4.7Aa & $4.7 \mathrm{Aa}$ & $4.7 \mathrm{Aa}$ & $4.7 \mathrm{Aa}$ & 4.7Aa & 4.7Aa \\
\hline 0.02 & $2.8 \mathrm{Ab}$ & $3.4 \mathrm{Ab}$ & 3.8Aab & $3.4 \mathrm{Ab}$ & $2.7 \mathrm{Ab}$ & 3.8Aab & $3.2 \mathrm{Ab}$ & $3.1 \mathrm{Ab}$ \\
\hline 0.04 & $2.8 \mathrm{Ab}$ & $2.2 \mathrm{Ac}$ & $3.3 \mathrm{Abc}$ & $3.3 \mathrm{Abc}$ & $2.6 \mathrm{Ab}$ & $3.0 \mathrm{Abc}$ & $2.0 \mathrm{Abc}$ & $3.0 \mathrm{Ab}$ \\
\hline 0.06 & $2.1 \mathrm{Ab}$ & $2.2 \mathrm{Ac}$ & $2.5 \mathrm{Acd}$ & 2.8Abcd & $2.1 \mathrm{Ab}$ & 2.1Acd & 1.9Abc & $2.3 \mathrm{Abc}$ \\
\hline 0.08 & $1.8 \mathrm{Abc}$ & $1.8 \mathrm{Ac}$ & $2.2 \mathrm{Ad}$ & $2.3 \mathrm{Acd}$ & $2.2 \mathrm{Ab}$ & 1.6Ade & 1.7Abc & $2.1 \mathrm{Abc}$ \\
\hline 0.10 & $1.6 \mathrm{ABbc}$ & $1.7 \mathrm{Ac}$ & $1.9 \mathrm{Ad}$ & $1.9 \mathrm{Ad}$ & $2.2 \mathrm{Ab}$ & 1.5ABde & $0.5 \mathrm{Bc}$ & $2.1 \mathrm{Abc}$ \\
\hline 0.20 & $0.8 \mathrm{ABCc}$ & $0.3 \mathrm{Cd}$ & $1.8 \mathrm{Ad}$ & 1.9Ad & $1.8 \mathrm{Ab}$ & $0.1 \mathrm{Ce}$ & $0.5 \mathrm{BCc}$ & $1.5 \mathrm{ABc}$ \\
\hline
\end{tabular}

A: Tween-20:PEG400(4.0:3.5).

Means in a column followed by the same uppercase letter and means in a row followed by the same lowercase letter are not significantly different $(\mathrm{P}<0.05)$ according to Duncan's multiple range test.

A comparative study on the use of plant-derived compounds to control different developmental stages of mite pests by Mwandila et al. (2013) found that syringa (Melia azedarach) seed extracts had acaricidal properties against adults, eggs, and nymphs of the red spider mite (Tetranychus spp.) Saad et al. (2017) also demonstrated that citronella EO induced ovipositional deterrence on B. tabaci. Unfortunately, no reports regarding the interference of surfactants on mite egglaying were found. 
For the repellency test, citronella grass and lemongrass nEOs at $0.06 \%$ to $0.10 \%$ had the highest repellent effectiveness of $85.0 \%$ to $95.0 \%$ repellence, and these values were not significantly different when compared to other treatments. However, it was apparent that at lower concentrations such as $0.02 \%$, clove nEOs and citral nMCs both showed $66.67 \%$ and $71.67 \%$ repellency, respectively. They were significantly different to others at the $95 \%$ confidence level $(\mathrm{P}<0.05)$ in which they responded as attractants to the African red mites up to $28.33 \%$ and $33.33 \%$, respectively (Table 4). There are few studies related to testing the repellency of the selected EOs against other mite pests. Kheradmand et al. (2015) reported that clove EO had the most potent repellent effect on the two-spotted spider mite (Tetranychus urticae). However, in the present study, it showed relatively low repellency to the tested mite, especially compared with citronella grass nEOs. Thein et al. (2013) also emphasized that crude citronella extract was the most repellent on the maize weevil (Sitophilus spp.) According to Lakyat et al. (2017), the repellent activity of lemongrass nEO at the very low concentration of $0.02 \%$ had the most repellent effect on adult brown planthopper (Nilaparvata lugens) with a $43.83 \%$ repellency index. Monoterpenes in EOs are cytotoxic to animal tissue, radically decrease mitochondria and Golgi body numbers, and damage the respiratory system (Lee et al., 1997). However, there is limited information about the physiological actions of EOs on insects or mites. Different EOs and their components seem to have a neurotoxic mode of action (Kostyukovsky et al., 2002).

Table 4. Percentage response of the African red mite to different concentrations of essential oil and main chemical compound nanoemulsions.

\begin{tabular}{|c|c|c|c|c|c|}
\hline \multirow[b]{3}{*}{ Emulsion } & \multirow[b]{2}{*}{ Concentration } & \multicolumn{2}{|c|}{ Response } & \multirow[b]{3}{*}{$\chi^{2}$} & \multirow[b]{3}{*}{$\mathrm{P}$} \\
\hline & & Repellency & Attraction & & \\
\hline & $\%$ & $\%$ & $\%$ & & \\
\hline \multicolumn{6}{|c|}{ Essential oil nanoemulsion } \\
\hline \multirow[t]{3}{*}{ Citronella grass } & 0.02 & 81.67 & 18.33 & 13.375 & $0.000 * *$ \\
\hline & 0.06 & 93.33 & 6.67 & 27.743 & $0.000 * *$ \\
\hline & 0.10 & 95.00 & 5.00 & 30.740 & $0.000 * *$ \\
\hline \multirow[t]{3}{*}{ Lemongrass } & 0.02 & 81.67 & 18.33 & 13.375 & $0.000 * *$ \\
\hline & 0.06 & 85.00 & 15.00 & 16.752 & $0.000^{* *}$ \\
\hline & 0.10 & 95.00 & 5.00 & 30.470 & $0.000^{* *}$ \\
\hline \multirow[t]{3}{*}{ Cinnamon } & 0.02 & 85.00 & 15.00 & 16.752 & $0.000 * *$ \\
\hline & 0.06 & 86.67 & 13.33 & 18.639 & $0.000 * *$ \\
\hline & 0.10 & 90.00 & 10.00 & 22.857 & $0.000 * *$ \\
\hline \multirow[t]{3}{*}{ Clove } & 0.02 & 66.67 & 33.33 & 3.429 & $0.641^{\mathrm{ns}}$ \\
\hline & 0.06 & 80.00 & 20.00 & 11.868 & $0.001 * *$ \\
\hline & 0.10 & 81.67 & 18.33 & 13.375 & $0.000 * *$ \\
\hline \multicolumn{6}{|c|}{ Main chemical compound nanoemulsion } \\
\hline \multirow[t]{3}{*}{ Geraniol } & 0.02 & 81.67 & 18.33 & 13.375 & $0.000 * *$ \\
\hline & 0.06 & 83.33 & 16.67 & 15.000 & $0.000 * *$ \\
\hline & 0.10 & 85.00 & 15.00 & 16.752 & $0.000 * *$ \\
\hline \multirow[t]{3}{*}{ Citral } & 0.02 & 71.67 & 28.33 & 5.911 & $0.150^{\mathrm{ns}}$ \\
\hline & 0.06 & 73.33 & 26.67 & 6.910 & $0.009 * *$ \\
\hline & 0.10 & 83.33 & 16.67 & 15.000 & $0.000 * *$ \\
\hline \multirow[t]{3}{*}{ Eugenol } & 0.02 & 70.00 & 30.00 & 5.000 & $0.025^{*}$ \\
\hline & 0.06 & 73.33 & 26.67 & 6.910 & $0.009 * *$ \\
\hline & 0.10 & 76.67 & 23.33 & 9.187 & $0.002 * *$ \\
\hline Control & & 30.00 & 30.00 & & \\
\hline
\end{tabular}

*** Significant difference at $\mathrm{P}<0.05$ and $\mathrm{P}<0.01$, respectively; ${ }^{\text {ns }}$ nonsignificant difference. 


\section{CONCLUSIONS}

Effectiveness testing in terms of acaricidal, egg-laying inhibition, and repellent properties of plant essential oil (EO) emulsions, nanoemulsions, and their main chemical compound nanoemulsions against the African red mite (Eutetranychus africanus) demonstrated that the citronella grass EO nanoemulsion at the $0.6 \%$ concentration was extremely toxic with $100 \%$ mite mortality. In addition, all the surfactants used at high concentrations also exhibited a high toxic effect on the mite. Geraniol, one of the main chemical compounds of citronella grass EO and citronella grass EO nanoemulsion at $0.2 \%$ showed potent egg-laying inhibition of the African red mite; the mean number of eggs laid by each female was 0.1 and 0.3 eggs, respectively, while 4.7 eggs were obtained in the control. Citronella grass and lemongrass EO nanoemulsions at $0.1 \%$ also showed a high repellency of $95 \%$ on the African red mite. Therefore, the citronella grass EO nanoemulsion is an appropriate substance to control the African red mite.

\section{ACKNOWLEDGEMENTS}

This research was supported by the Thai government 2017 fiscal year budget via Faculty of Agricultural Technology, King Mongkut's Institute of Technology Ladkrabang, under the research project of Natural Products for Pest Control Research Center.

\section{REFERENCES}

Abbott, W.S. 1925. A method of computing the effectiveness of an insecticide. Journal of the American Mosquito Control Association 3:302-303.

Attia, S., Grissa, L.K., Lognay, G., Bitume, E., Hance, T., and Mailleux, A.C. 2013. A review of the major biological approaches to control the worldwide pest Tetranychus urticae (Acari: Tetranychidae) with special reference to natural pesticides. Journal of Pest Science 86:361-386. doi:10.1007/s10340-013-0503-0.

Beyzavi, G., Ueckermann, E.A., Faraji, F., and Ostovan, H. 2013. A catalog of Iranian prostigmatic mites of superfamilies Raphignathoidea \& Tetranychoidea (Acari). Persian Journal of Acarology 2(3):389-474.

Chung, S.K., Seo, J.Y., Lim, J.H., Park, H.H., Yea, M.J., and Park, H.J. 2013. Microencapsulation of essential oil for insect repellent in food packaging system. Journal of Food Science 78(5):709-714. doi:10.1111/1750-3841.12111.

Danaei, M., Dehghankhold, M., Ataei, S., Hasanzadeh Davarani, F., Javanmard, R., Dokhani, A., et al. 2018. Impact of particle size and polydispersity index on the clinical applications of lipidic nanocarrier systems. Pharmaceutics 10(2):57. doi:10.3390/pharmaceutics 10020057.

Gao,F.,Zhang,Z.,Bu,H.,Huang,Y.,Gao,Z., and Shen, J.2011. Nanoemulsion improves the oral absorption of candesartan cilexetil in rats: Performance and mechanism. Journal of Controlled Release 149(2):168-74. doi:10.1016/j.jconrel.2010.10.013.

Hamzah, M.H., Man, H.C., Abidin, Z.Z., and Jamaludin, H. 2013. Comparison of citronella oil extraction methods from Cymbopogon nardus grass by ohmic-heated hydro-distillation, hydro-distillation, and steam distillation. Bioresources 9(1):256-272. doi:10.15376/biores.9.1.256-272.

Insung, A., Pumnuan, J., Mahakittikun, V., and Wangapai, T. 2016. Effectiveness of essential oils of medicinal plants at reducing the amounts of allergen produced by the European house dust mite, Dermatophagoides pteronyssinus (Trouessart). Journal of Acarological Society of Japan 25(1):179-184.

Jintapattanakit, A. 2018. Preparation of nanoemulsions by phase inversion temperature (PIT) method. Pharmaceutical Sciences Asia 45(1):1-12. doi:10.29090/psa.2018.01.001.

Khanjani, M., Khanjani, M., and Seeman, O.D. 2017. New spider mites (Acari: Tetranychidae) of the genera Paraplonobia and Eurytetranychus from Iran, and a description of all life stages of Eutetranychus orientalis (Klein). Acarologia 57(3):465-491. doi:10.24349/acarologia/20174167.

Kheradmand, K., Beynaghi, S., Asgari, S., and Sheykhi Garjan, A. 2015. Toxicity and repellency effects of three plant essential oils against two-spotted spider mite, Tetranychus urticae (Acari: Tetranychidae). Journal of Agricultural Science and Technology 17:1223-1232.

Komaiko, J., and McClements, D.J. 2015. Low-energy formation of edible nanoemulsions by spontaneous emulsification: Factors influencing particle size. Journal of Food Engineering 146:122-128. doi:10.1016/j.jfoodeng.2014.09.003.

Kostyukovsky, M., Rafaeli, A., Gileadi, C., Demchenko, N., and Shaaya, E. 2002. Activation of octopaminergic receptors by essential oil constituents isolated from aromatic plants: possible mode of action against insect pests. Pest Management Science 58(11):1101-1106. doi:10.1002/ps.548. 
Kwon, S.S., Kong, B.J., Cho, W.G., and Park, S.N. 2015. Formation of stable hydrocarbon oil-in-water nanoemulsions by phase inversion composition method at elevated temperature. Korean Journal of Chemical Engineering 32(3):540-546. doi:10.1007/s11814-014-0234-9.

Lakyat, A., Pumnuan, J., and Insung, A. 2017. Effectiveness of nano plant essential oils against brown planthopper, Nilaparvata lugens (Stål). International Journal of Agricultural Technology 13(7.2):1537-1546.

Lee, S., Tsao, R., Peterson, C., and Coats, J.R. 1997. Insecticidal activity of monoterpenoids to the western corn root worm (Coleoptera: Chrysomelidae), two spotted spider mite (Acari: Tetranychidae) and housefly (Diptera: Muscidae). Journal of Economic Entomology 90(4):883-892. doi:10.1093/jee/90.4.883.

Lertsutthiwong, P., and Rojsitthisak, P. 2011. Chitosan-alginate nanocapsules for encapsulation of turmeric oil. Pharmazie 66(12):911-915. doi:10.1691/ph.2011.1068.

Liburd, O., and Rhodes, E. 2019. Management of strawberry insect and mite pests in greenhouse and field crops. In Asao, T., and Asaduzzaman, Md. (eds.) Strawberry. Pre- and post-harvest management techniques for higher fruit quality. IntechOpen doi:10.5772/intechopen.82069.

Marsalek, R. 2014. Particle size and zeta potential of ZnO. APCBEE Procedia 9:13-17. doi:10.1016/j.apcbee.2014.01.003.

McClements, D.J. 2011. Edible nanoemulsions: fabrication, properties, and functional performance. Soft Matter 7(6):2297-2316. doi:10.1039/C0SM00549E.

Mwandila, N.J.K., Olivier, J., Munthali, D., and Visse, D. 2013. Efficacy of syringa (Melia azedarach L.) extracts on eggs, nymphs and adult red spider mites, Tetranychus spp. (Acari: Tetranychidae) on tomatoes. African Journal of Agricultural Research 8(8):695-700.

Pumnuan, J., and Insung, A. 2016a. Fumigant toxicity of lemon grass, citronella grass and black pepper essential oils against mushroom mite (Dolichocybe indica Mahunka). International Journal of Agricultural Technology 12(5):893-898.

Pumnuan, J., and Insung, A. 2016b. Fumigation toxicity of plant essential oils in controlling thrips, Frankliniella schultzei (Thysanoptera: Thripidae) and mealybug, Pseudococcus jackbeardsleyi (Hemiptera: Pseudococcidae). Journal of Entomological Research 40(1):1-10.

Rice, S.B., Chan, C., Brown, S.C., Eschbach, P., Han, L., Ensor, D.S., et al. 2013. Particle size distributions by transmission electron microscopy: an interlaboratory comparison case study. Metrologia 50(2013):663-678. doi:10.1088/0026-1394/50/6/663.

Saad, K.A., Idris, A.B., and Mohamad Roff, M.N. 2017. Toxic, repellent, and deterrent effects of citronella essential oil on Bemisia tabaci (Hemiptera: Aleyrodidiae) on chili plants. Journal of Entomological Science 52(2). doi:10.18474/JES16-32.1.

Saenmanot, S., Insung, A., Pumnuan, J., Tawatsin,A., Thavara, U., Phumee, A., et al. 2018. Insecticidal activity of Thai botanical extracts against development stages of German cockroach, Blattella germanica (L.) (Orthoptera: Blattellidae). Southeast Asian Journal of Tropical Medicine and Public Health 49(1):46-59.

Sarapothong, K., Pumnuan, J., and Insung. A. 2017. Acaricidal toxicity of nano essential oil of black pepper against African red mite (Eutetranychus africanus (Tucker)). International Journal of Agricultural Technology 13(7.3):2267-2274.

Silva, C.F., Moura, F.C., Mendes, M.F., and Pessoa, F.L.P. 2011. Extraction of citronella (Cymbopogon nardus) essential oil using supercritical $\mathrm{CO}_{2}$ : experimental data and mathematical modeling. Brazilian Journal of Chemical Engineering 28(2):343-350. doi:10.1590/S0104-66322011000200019.

Solans, C., and Solé, I. 2012. Nano-emulsions: Formation by low-energy methods. Current Opinion in Colloid \& Interface Science 17(5):246-254. doi:10.1016/j.cocis.2012.07.003.

Sruthi, B.Y.K., Gurupadayya, B.M., Sairam, K.V., and Kumar, T.N. 2014. Development and validation of GC method for the estimation of eugenol in clove extract. International Journal of Pharmacy and Pharmaceutical Sciences 6(2):473-476.

Thein, W.M., Javier, P.A., and Ceballo, F.A. 2013. Insecticidal activity of crude plant extracts against Sitophilus spp. (Coleoptera: Curculionidae) and Callosobruchus chinensis (L.) (Coleoptera: Bruchidae). Philippine Agricultural Scientist 96(2):154-162.

Tirello, P., Pozzebon, A., Cassanelli, S., Van Leeuwen, T., and Duso, C. 2012. Resistance to acaricides in Italian strains of Tetranychus urticae: toxicological and enzymatic assays. Experimental and Applied Acarology 57(1):53-64. doi:10.1007/s10493-012-9536-y.

Uddin, M.A., Shahinuzzaman, M., Rana, M.S., and Yaakob, Z. 2017. Study of chemical composition and medicinal properties of volatile oil from clove buds (Eugenia caryophyllus). International Journal of Pharmaceutical Sciences and Research 8(2):895-899. doi:10.13040/IJPSR.0975-8232.8(2).895-899. 